\title{
Detection of the quantitative trait loci for $\alpha$-amylase activity on a high-density genetic map of rye and comparison of their localization to loci controlling preharvest sprouting and earliness
}

\author{
Beata Myśków · Stefan Stojałowski • Anna Lań • \\ Hanna Bolibok-Brągoszewska • \\ Monika Rakoczy-Trojanowska $\cdot$ Andrzej Kilian
}

Received: 6 May 2011/Accepted: 24 August 2011/Published online: 28 September 2011

(C) The Author(s) 2011. This article is published with open access at Springerlink.com

\begin{abstract}
The objectives of the research were to determine the position of quantitative trait loci (QTL) for $\alpha$-amylase activity on the genetic map of a rye recombinant inbred line population-S120 $\times$ S76and to compare them to known QTL for preharvest sprouting and heading earliness. Fourteen QTL for $\alpha$ amylase activity on all seven chromosomes were identified. The detected QTL were responsible for $6.09-23.32 \%$ of $\alpha$-amylase activity variation. The lowest LOD value (2.22) was achieved by locus QAa4R-M3 and the highest (7.79) by locus QAa7RM1. Some QTL intervals for features of interest
\end{abstract}

Electronic supplementary material The online version of this article (doi:10.1007/s11032-011-9627-1) contains supplementary material, which is available to authorized users.

B. Myśków ( $\varangle)$ · S. Stojałowski · A. Łań

Department of Plant Genetics, Breeding and

Biotechnology, West-Pomeranian University of

Technology in Szczecin (ZUT), ul. Słowackiego 17,

71-434 Szczecin, Poland

e-mail: bmyskow@zut.edu.pl

H. Bolibok-Brągoszewska · M. Rakoczy-Trojanowska

Department of Plant Genetics, Breeding and

Biotechnology, Warsaw University of Life Sciences

(SGGW), ul. Nowoursynowska 159, 02-776 Warszawa,

Poland

\section{A. Kilian}

Triticarte P/L and Diversity Arrays Technology P/L, PO

Box 7141, Yarralumla, Canberra, ACT 2600, Australia overlapped partially or completely. There were six overlapping QTL for $\alpha$-amylase activity and preharvest sprouting (on $1 \mathrm{R}, 3 \mathrm{R}, 4 \mathrm{R}, 6 \mathrm{R}, 7 \mathrm{R}$ ) and the same number for preharvest sprouting and heading earliness (on $1 \mathrm{R}, 2 \mathrm{R}, 6 \mathrm{R}, 7 \mathrm{R}$ ). Furthermore, there was one interval partially common to all three traits, mapped on the long arm of chromosome 1R. Testing of lines originating from hybrid breeding programs, such as S120 and S76, may provide important information about the most significant genes and markers for selection in commercial breeding. Among the statistically significant markers selected in the KruskalWallis test $(P<0.005)$, there were 55 common ones for preharvest sprouting and heading earliness $(1 \mathrm{R}, 2 \mathrm{R}$, 6R), 30 markers coinciding between $\alpha$-amylase activity and preharvest sprouting $(5 R, 7 R)$ and one marker for $\alpha$-amylase activity and heading earliness (6R).

Keywords $\alpha$-amylase - DArT - Heading earliness . High density genetic map · Preharvest sprouting · QTL · RIL · Rye

\section{Introduction}

Recent advances in molecular marker technology and the development of high-density molecular marker linkage maps have provided powerful tools for elucidating the genetic basis of quantitatively inherited traits (Kunpu et al. 2009). The first highresolution map of rye constructed with the use of 
Diversity Arrays Technology (DArT) (Jaccoud et al. 2001) was created in 2009 (Bolibok-Brągoszewska et al. 2009). The next high-density linkage map of rye, based on DArT and PCR markers, was recently used for detecting quantitative trait loci (QTL) for preharvest sprouting (PHS) and heading earliness (Myśków 2011). These agriculturally important traits are connected with two crucial events in the plant's life cycle. First is the end of dormancy and seedling emergence, because until then there is no photosynthesis and plants cannot gain mass. The second event is anthesis which is important because it determines the time of grain maturity during the season (Jamieson et al. 1998). The appropriate timing of flowering is a critical adaptive trait for the propagation and survival of a plant species. It should be late enough to avoid frequent exposure of the sensitive reproductive organs to freezing temperatures early in the season, but not so late as to expose the crop to damaging drought conditions and high temperatures during anthesis and grain filling (Chen et al. 2009). Premature breaking of dormancy can result in PHS of spikes in wet weather conditions. PHS is a major cause of excess $\alpha$-amylase activity (AA), which impairs grain quality since enzymatic hydrolysis of starch during food manufacture can lead to processing problems and unsatisfactory end products (Graybosch et al. 2000; Lunn et al. 2001; Mares et al. 2002; Tjin Wong Joe et al. 2005). Much research on wheat grains has proved that there are a number of additional causes for the deterioration of meal properties, which reflects low falling number. These include late maturity $\alpha$-amylase (LMA) (Mrva and Mares 1996a, b, 1999, 2002, 2008), also known as prematurity $\alpha$-amylase (PMAA) in the UK (Lunn et al. 2001; Tjin Wong Joe et al. 2005), and retained pericarp $\alpha$-amylase (RPAA) (Lunn et al. 2001).

It is well established that the genetic mechanism of AA, PHS and heading/flowering in crops is complex. Earliness is controlled by photoperiodic response, chilling requirement and narrow sense earliness. Each of these components are under the control of multiple loci, localized on most of the wheat and barley (bibliography in: Cockram et al. 2007; Kunpu et al. 2009) and all rye chromosomes (Plaschke et al. 1993; Masojć and Milczarski 1999; Börner et al. 2000; Korzun et al. 2001; Stojałowski and Łapiński 2002; Myśków 2011). All chromosomes of Triticeae are also involved in determining PHS and AA
(Masojć and Milczarski 2005, 2009, and bibliography therein).

Extensive research involving crop species has been conducted on the relationship between flowering time (heading date), plant adaptation and yield (Laurie 1997). Several data suggest that loci controlling photoperiod response, vernalization requirement and earliness per se may exert pleiotropic effects on yield and yield-related traits (Worland et al. 1998; Buck-Sorlin and Börner 2001; Lewis et al. 2008). Studies of QTL controlling PHS and AA in rye demonstrated that these two systems coincide in great part (Masojć and Milczarski 2005, 2009; Masojć et al. 2011). Partial overlap between QTL for heading earliness (HE) and PHS in rye has been found by Myśków (2011). However, a combined relationship between AA, PHS and earliness has not been defined yet. The objectives of our research were to determine the position of QTL for AA on the genetic map of a rye recombinant inbred line (RIL) population-S120 $\times$ S76-and to compare them to known QTL for PHS and HE.

\section{Materials and methods}

The mapping population of $\mathrm{S} 120 \times \mathrm{S} 76$ consisted of 143 genotypes of the RIL-F8 generation. The pedigree of parental inbred lines is described in Myśków et al. (2001). S120 and S76 differ in values of AA, PHS and time of ear emergence.

The genetic map of the S120 × S76 RIL population has been constructed by Myśków (2011) with the use of JoinMap 3.0 software (Van Ooijen and Vorrips 2001). All seven linkage groups comprised 1285 DArT loci and 62 PCR-based loci. Individual chromosomes included from 123 (5R) to 261 (6R) loci, and spanned distances of $76 \mathrm{cM}(3 \mathrm{R})$ to $233 \mathrm{cM}(1 \mathrm{R})$. The whole map length was $962 \mathrm{cM}$ and the average density varied from 0.9 to 2.4 markers/cM (average distance $0.4-1.1 \mathrm{cM})$.

AA was analyzed during the period 2008-2010, for self-pollinated plants of the RIL-F8 to RIL-F10 generations. Plant material was grown in an experimental field at the West Pomeranian University of Technology in Szczecin, Poland. Each RIL was represented by $1-8$ spikes (4-5 for most genotypes) from different plants. Equal amounts of flour (250 mg) obtained from all seeds with no visible 
signs of sprouting were used for AA determination. The method of estimating the level of AA was described by Masojć and Larsson-Raźnikiewicz (1991). Additionally, PHS was measured in the year 2010 as a percentage of growing seeds per total seeds in the ear, after watering of ten mature, harvested spikes, according to the method described by Masojć et al. (2007).

Statistical analysis was carried out using the STATISTICA version 9.0 package (http://www. statsoft.com). Broad-sense heritability $\left(h^{2}\right)$ was calculated using the formula $h^{2}=V_{G} / V_{F}$, where $V_{G}$ is the genetic variance estimated as a difference between $V_{F}$ and $V_{E} ; V_{F}$ is the RIL population variance, $V_{E}$ is the mean variance of parental lines S120 and S76, estimated with using at least ten plants of each one.

The significance of difference between parental lines trait values was established by employing the Cochran and Cox test.

The relationship between segregations of single marker and trait was analyzed with the KruskalWallis test using MapQTL 5.0 package (Van Ooijen 2004).

Linkage analysis was performed using the composite interval mapping (CIM) method (Zeng 1994) with Windows QTL Cartographer version 2.51 (http://www.statgen.ncsu.edu/qtlcart/ WQTLCart.htm, Wang et al. 2007). The step size chosen for all QTL was $2 \mathrm{cM}$. Significant thresholds for declaring the presence of a QTL were estimated from 1,000 permutations of the data (Doerge and Churchill 1996).
Results of composite interval mapping performed on the data of AA and new data of PHS were compared with localization of QTL for PHS and HE obtained previously by Myśków (2011) with the use of the same genetic map of the S120 $\times$ S76 RIL population.

\section{Results}

Phenotypic variation and correlation analysis

Parental phenotypic variation and the distribution among RILs for AA, PHS and HE in different years are shown in Table 1. Parental lines differed significantly $(P=0.001)$ with respect to PHS and HE, but not significantly in the case of AA values. The measured target traits varied in the RIL population following a continuous distribution representing a normal phenotypic segregation for QTL mapping. All trait value ranges were higher in the RIL population than in both parents, suggesting that transgression was observed. The estimated heritability of AA, HE and PHS was $24.7,34.5$ and $46.7 \%$, respectively.

Pairwise correlation coefficients between the traits are given in Table 2. Significant correlations were observed between result data obtained in all years for PHS, and for almost all variants of HE and for AA assessed in 2008 and 2009. There was no correlation found between different traits, except one-between AA and PHS during the 2009 season.
Table 1 Characteristics of $\alpha$-amylase activity (AA), preharvest sprouting (PHS) and heading earliness (HE), in mapping population $\mathrm{S} 120 \times \mathrm{S} 76$

\begin{tabular}{|c|c|c|c|c|c|}
\hline \multirow[t]{2}{*}{ Trait } & \multicolumn{2}{|c|}{ Mean value \pm standard error for parental line } & \multirow[t]{2}{*}{ Year } & \multirow{2}{*}{$\begin{array}{l}\text { Mean value } \\
\text { in population }\end{array}$} & \multirow{2}{*}{$\begin{array}{l}\text { Variation } \\
\text { range in } \\
\text { population }\end{array}$} \\
\hline & $\mathrm{S} 120$ & S76 & & & \\
\hline \multirow[t]{3}{*}{ AA $(\mathrm{mm})$} & \multirow[t]{3}{*}{$9.3 \pm 0.7$} & \multirow[t]{3}{*}{$10.6 \pm 0.8$} & 2008 & 10.1 & $6-16.5$ \\
\hline & & & 2009 & 11.4 & $6-16$ \\
\hline & & & 2010 & 10.2 & $6-19$ \\
\hline \multirow[t]{4}{*}{ PHS (\%) } & \multirow[t]{4}{*}{$68.1 \pm 1.3$} & \multirow[t]{4}{*}{$25.6 \pm 1.3$} & 2007 & 28.1 & $0-88.9$ \\
\hline & & & 2008 & 37.9 & $0-100$ \\
\hline & & & 2009 & 41.4 & $0-100$ \\
\hline & & & 2010 & 48.8 & $0-100$ \\
\hline \multirow[t]{4}{*}{$\mathrm{HE}\left({ }^{\circ}\right)$} & \multirow[t]{4}{*}{$7.4 \pm 0.2$} & \multirow[t]{4}{*}{$3.1 \pm 0.2$} & 2007 & 6.4 & $1-9$ \\
\hline & & & 2008 & 4.7 & $1-9$ \\
\hline & & & 2009 & 5.0 & $1-9$ \\
\hline & & & 2010 & 5.8 & $1-9$ \\
\hline
\end{tabular}




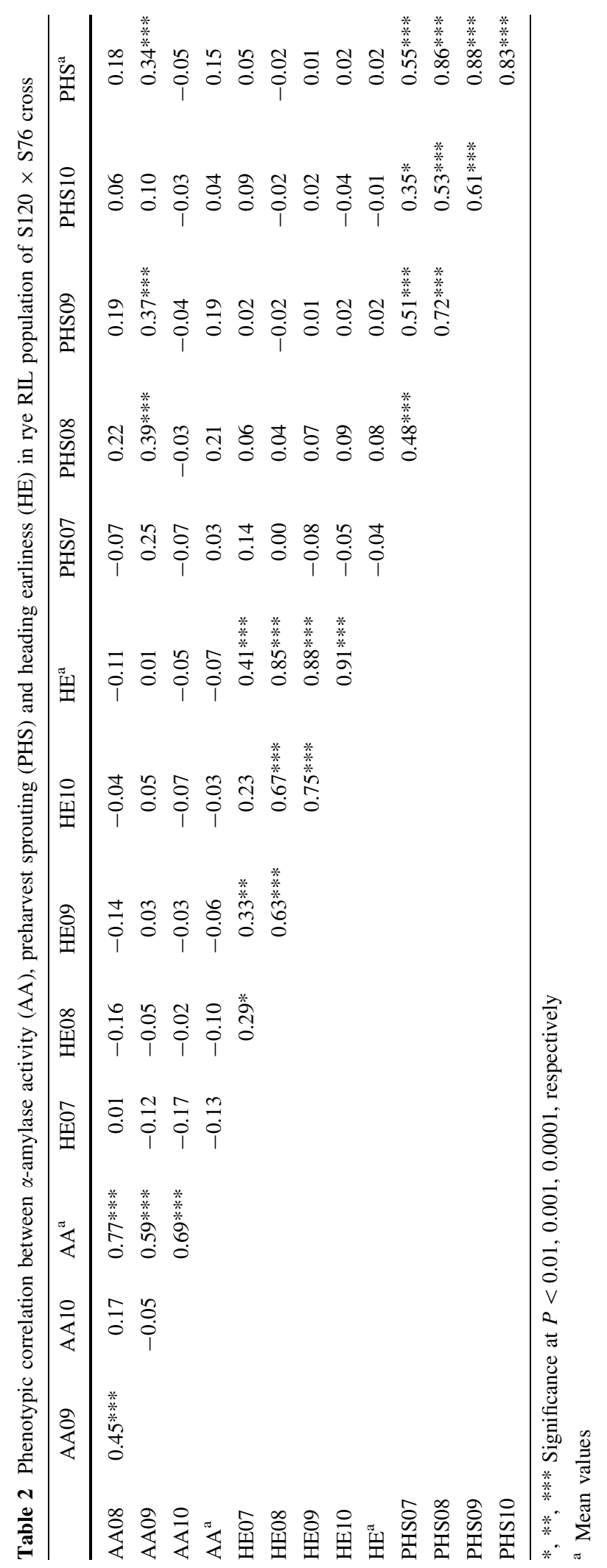


QTL analysis

Putative QTL for AA detected in each year (2008-2010) and as a result of average values of all seasons are listed in Table 3. This table contains information about QTL for PHS detected in 2010 and those based on the mean values of the trait (2007-2010). Fourteen QTL for AA on all seven chromosomes and seven QTL involving chromosomes $3 \mathrm{R}, 5 \mathrm{R}$ and $6 \mathrm{R}$ for PHS were identified. Detected QTL were responsible for $6.09-23.32 \%$ and $7.51-17.08 \%$ of AA and PHS variation, respectively. The lowest LOD value of 2.22 was achieved by locus QAa4R-M3 and the highest-7.79-by locus QAa7R-M1. The range of LODs of QTL peaks for PHS varied from 2.35 to 4.32. Most of the alleles increasing AA were contributed by line S120. Four of the seven alleles enhancing PHS originated from parent S76. Three of them were localized on the 6RL chromosome close to each other (Fig. 1).

None of the QTL controlling AA were identified in 2 years. However, three of them were confirmed by the detection on the basis of mean values (Table 3). Three of the QTL for PHS detected in 2010 were mapped in an earlier study (Myśków 2011) and the fourth was found additionally using the mean score over all years (Table 3 ).

Eighteen of 20 segregations of markers most strongly linked to the QTL were significantly associated with segregations of AA or PHS, as revealed by the Kruskal-Wallis test; six of them were significant at $P<0.001$ (Table 3).

The locations of all QTL for AA, PHS and HE in the RIL population of S120 $\times$ S76 are shown in Fig. 1 and in Electronic Supplementary Material 1. If any locus was found in different years, it was presented only as a single rectangle and counted as a single QTL. There were 14 QTL detected for AA, 33 for PHS and 17 for HE. Considering QTL revealed twice (in 2 years or both in 1 year and as a result obtained on the basis of the average data), there were 4, 16 and 9 loci, for AA, PHS and HE, respectively.

Co-localization of QTL and common markers

Some QTL intervals for measured features overlapped partially or completely (Fig. 1, Supplement 1). There were six overlapping QTL for AA and PHS (on 1R, $3 R, 4 R, 6 R, 7 R$ ) and the same number for PHS and $H E$ (on $1 \mathrm{R}, 2 \mathrm{R}, 6 \mathrm{R}, 7 \mathrm{R}$ ). Furthermore, there was one interval partially common to all three traits, mapped on the long arm of chromosome 1R.

Among the statistically significant markers selected using the Kruskal-Wallis test $(P<0.005)$, there were 55 common ones for PHS and heading earliness: 29 located on chromosome 1R, 10 from linkage group 2R and 16 from chromosome 6R. There were 30 coincident markers identified between AA and PHS (one from linkage group 5R, the rest from 7R). There was one significant marker for AA and HE (6R). Markers common to two traits of interests are listed in Supplement 2.

\section{Discussion}

In rye, QTL mapping for AA and PHS has been an area of intense research, which has led to the identification of many loci and to the discovery of the phenomenon of overlapping intervals of QTL for these two traits (Masojć and Milczarski 2005, 2009). A large number of QTL showed relatively small effects and only a few major QTL with large phenotypic effects were previously identified. This presents a serious challenge when using single QTL with small effects for markerassisted selection (MAS), and therefore there is a need to pay more attention to exploring those stable QTL detected in different environments/seasons and different genetic backgrounds and those revealing pleiotropic effects (Wang et al. 2009). The present research is an extension of earlier studies on AA and PHS and a summary of results from QTL analysis of AA, PHS and HE. This is the first attempt to use a high-density genetic map of rye for QTL analysis of these three important traits. It provides more opportunities for the identification of markers tightly linked to the target features. The study highlights the importance of some co-localized QTL, which could show the direction of studies on pleiotropic effects. The first case of application of an advanced RIL population in research on rye allowed for verification and phenotypic assessment in different environments.

\section{AA QTL}

Since in our study seeds were harvested at the stage of full ripeness, the majority of the $\alpha$-amylase developed 


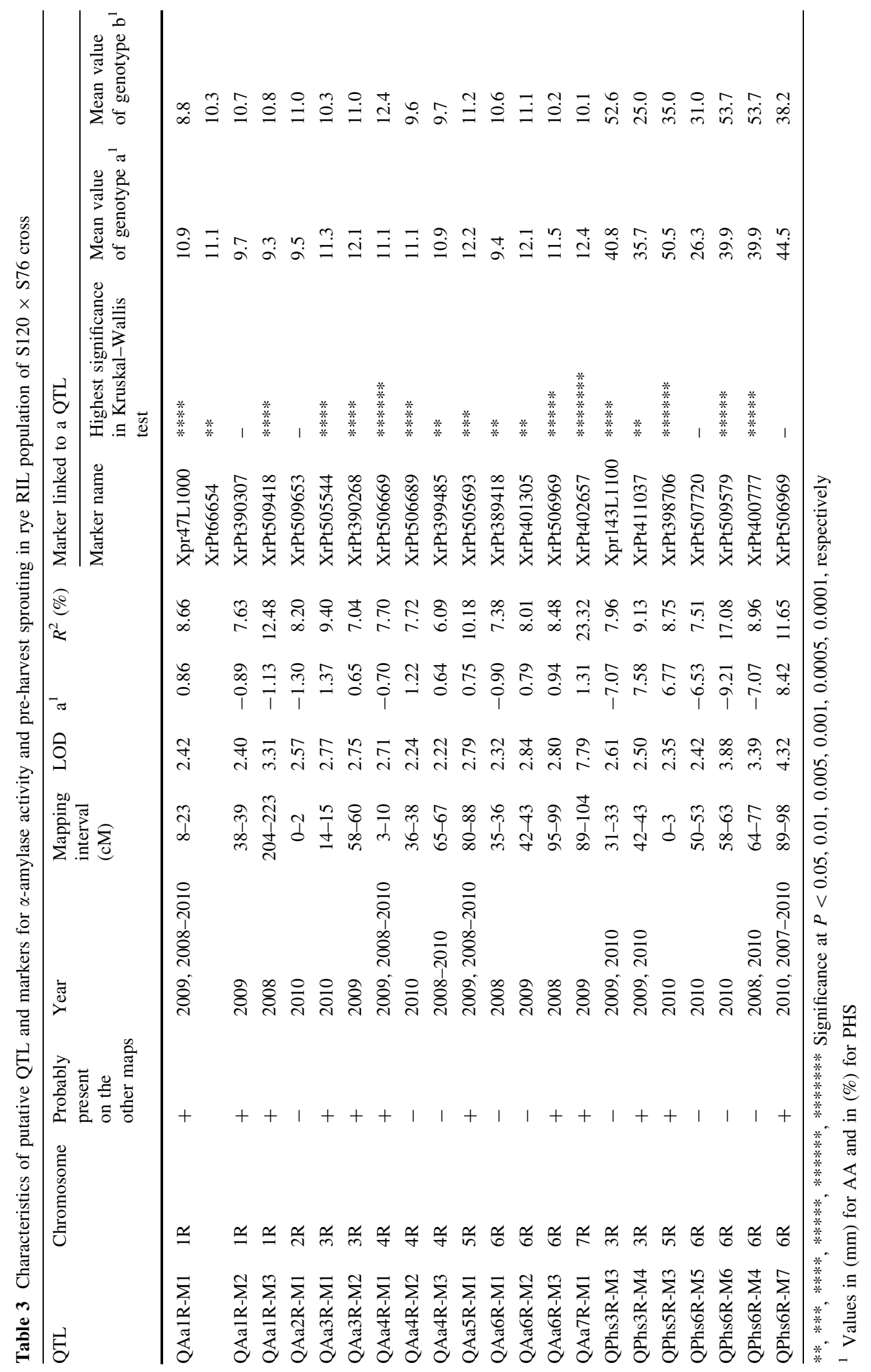




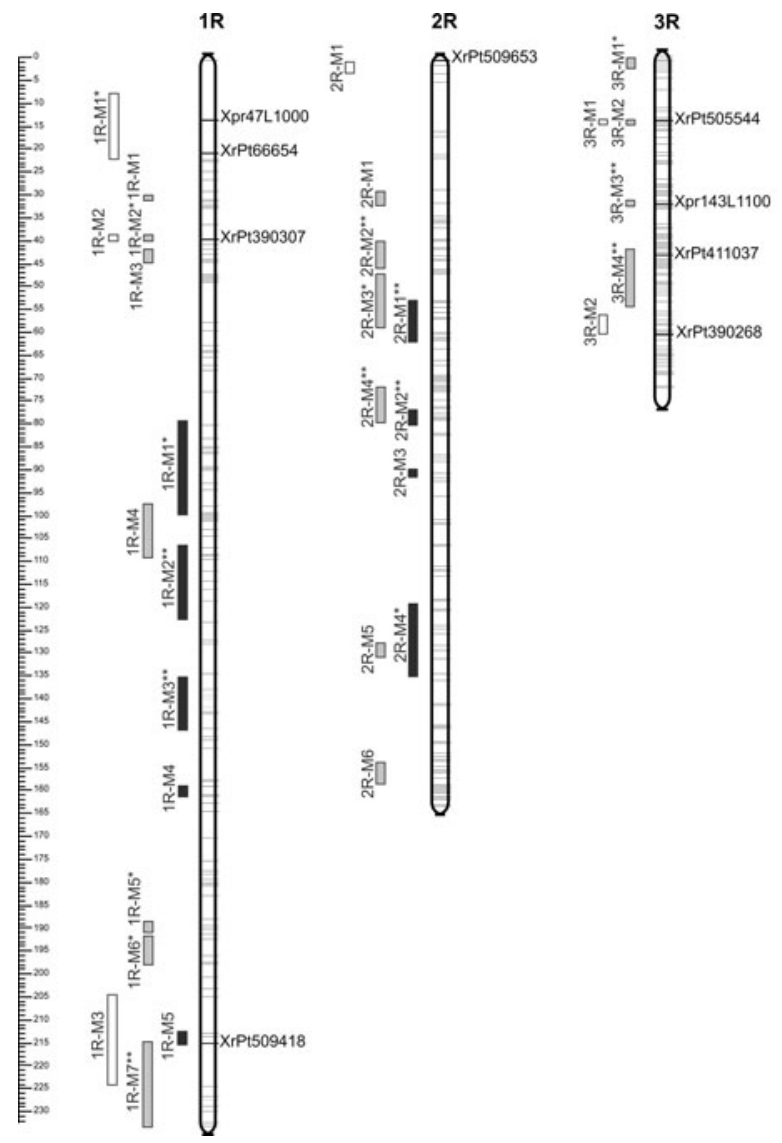

Fig. 1 Localization of $\alpha$-amylase activity QTL (white rectangles) and QTL for preharvest sprouting (grey rectangles) revealed in 2010 on the linkage map of S120 $\times$ S76 RIL population and their alignment with QTL for preharvest sprouting (grey rectangles) and heading earliness (black rectangles) detected previously (Myśków 2011). QTL detected

should represent LMA, which was shown to be the $\alpha$ AMY1 group of isozymes (Mrva and Mares 1999, 2002; Mares and Mrva 2008).

In order to find out whether the AA QTL reported here correspond to any of the known QTL, the map used in the present study was aligned to the other published genetic maps used in studies of QTL for AA and PHS. Nine out of 14 AA QTL reported here were probably mapped in the regions previously indicated in studies performed in two other rye populations (Masojć and Milczarski 2005, 2009). QAa7R-M1 seems to be the most important due to its highest LOD of 7.79 and because it explained as much as $23 \%$ of AA. The DArT marker $\mathrm{XrPt} 402657$ linked to this QTL was statistically significantly
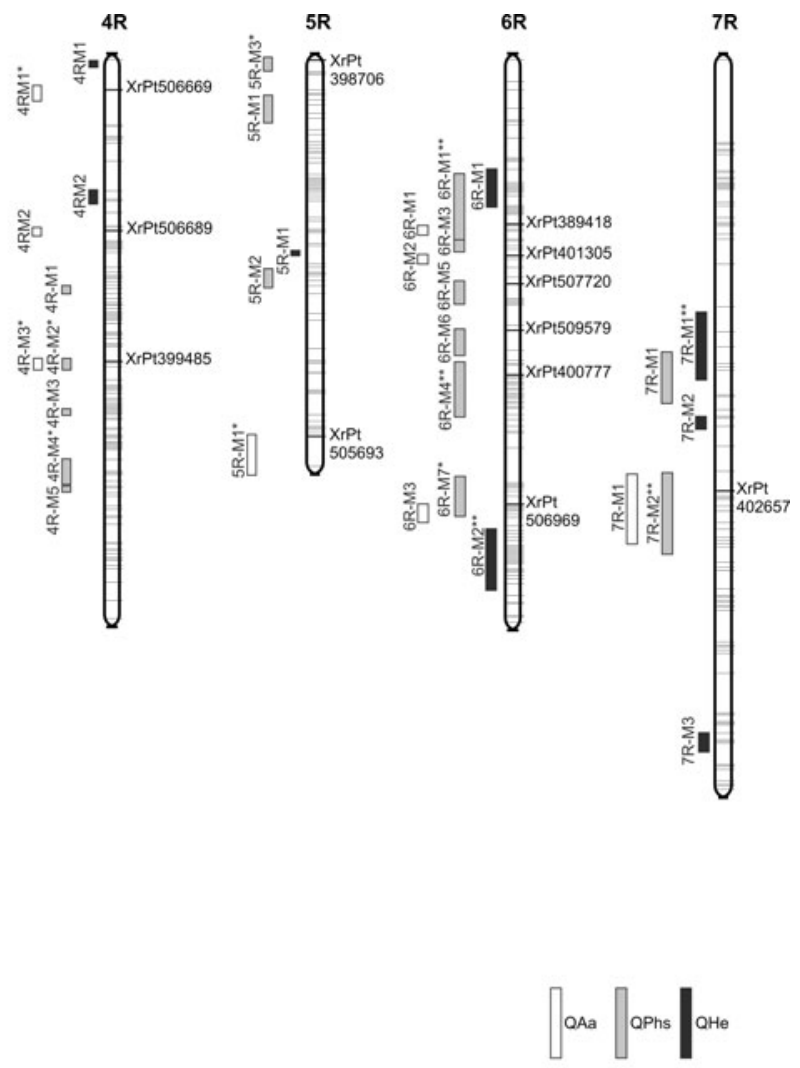

both in 1 year and on the base of mean values are indicated by one asterisk, QTL detected in two seasons are indicated by two asterisks. The ruler on the left side shows map distances in $\mathrm{cM}$. Markers situated on the right of each linkage group are those most strongly linked to the newly detected QTL. All markers from the map are listed in Supplement 1

related to the trait at $P<0.0001$ and it separates the genotypes into two groups with differing values of AA.

The most recent report on loci linked to AA detected using bidirectional selective genotyping (BSG) method coupled with molecular mapping (Masojć et al. 2011) pointed to seven markers distributed on the long arm of chromosome 7R. QAa7R-M1 may contain one or a few of them. However, the loci revealed therein were considered to be the ones with minor value for AA synthesis; the approach presented by that team did not allow for estimated parameters obtained by QTL analysis. BSG gives no information about the relative magnitude of the QTL effects acting in favour of the valuable trait 
(Masojć et al. 2011). In a recently published report on localization of genes affecting AA (Tenhola-Roininen et al. 2011), only one QTL was detected in breeding materials analyzed, on the long arm of chromosome 5R. Interestingly, the coinciding locus detected by Masojć et al. (2011) was considered to belong to the hypostatic, less important class of loci. This leads to the question whether research performed only on genotypes very different with respect to AA and PHS, such as lines 541 and Ot1-3 used by Masojć et al. (2011), properly reflects the genetic diversity of actual breeding materials. Testing of populations developed from crosses between cultivars like Amilo and Voima (Tenhola-Roininen et al. 2011) or lines originating from hybrid breeding program, such as S120 and S76, may provide important information about the most significant genes and markers for selection in commercial breeding.

In the past, it has been suggested that the QTL identified in more than one environment or those identified using data pooled over environments are useful from the point of view of MAS. Furthermore, for use in MAS, it is desirable to have one or a few QTL, each with a major effect on the trait (Kulwal et al. 2005). In the light of this observation, the QTL from chromosome 7R with DArT marker XrPt402657 and the next eight QTL detected in the present study and reported previously should prove valuable in MAS aimed at improving the grain quality of rye in terms of decrease in AA.

Interestingly, QTL analysis performed on the F2-F3 populations of $\mathrm{S} 120 \times \mathrm{S} 76$ (Myśków et al. 2010) allowed for the detection of only one QTL for AA, not corresponding to any of the QTL for AA revealed in the present study.

The comparable or even higher number of QTL for AA on the map presented compared to the results in other rye maps suggested that there is no need to detect significant differences between values of the trait of parental lines in QTL analysis. Both high- and lowactivity QTL alleles were found in each parental line, which explains the similarity of the mean values of both lines and the appearance of transgressive recombinants in the segregating population. The lack of repeatable QTL through the years reflects the low heritability of AA. However, it does not diminish the importance of the QTL, since they are confirmed in different genetic backgrounds.

\section{PHS QTL}

Out of the seven QTL for PHS detected in 2010, three were homeologous to the loci from the same map identified before (Myśków 2011). One of these three loci, $Q P h s 3 R-M 4$, was probably detected either in the F2 population of $\mathrm{S} 120 \times \mathrm{S} 76$, as a Phs1 (Myśków et al. 2010). However, QPhs5R-M3 was revealed in one season only; it probably coincided with $P h s 2$ from the F2 population and with QTL for PHS or AA mapped on chromosome 5R, near the structural locus of $\alpha$-amylase in other populations (Masojć et al. 2007, Masojć and Milczarski 2009). A marker linked to this

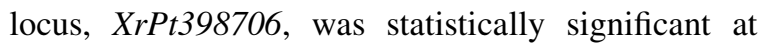
$P<0.0005$. The next QTL apparently important was QPhs6R-M7 from group 6R, due to its identification using pooled data, its expression in different genetic backgrounds and because its interval overlapped with the region containing a locus controlling AAQAa6R-M3.

In total 33 QTL for PHS were detected on the present map, 17 of them identified in at least two seasons. Similar to the case of QTL for AA analysis, this number exceeds the quantity of loci known from the earlier studies using the CIM method in a S120 × S76-F2 population (Myśków et al. 2010) and two others (Masojć and Milczarski 2009). This could partially be a result of different threshold values of LOD obtained with the permutation test in the present study and threshold values used in previously published reports (LOD $=3.0$ ). This could also be the consequence of using a high-density map and more abundant RIL population. Even if the new QTL are of less importance, they add important information to the growing knowledge concerning PHS resistance and AA in rye.

\section{HE QTL}

Exploiting the high-density map of the $\mathrm{S} 120 \times \mathrm{S} 76$ population resulted in detection of 17 QTL for HE falling on all chromosomes except 3R (Myśków 2011). Ten of them were identified in two seasons at least. This was the first report on QTL controlling earliness mapped on chromosome $1 \mathrm{R}$ in rye. There were therefore at least five new loci detected. $Q H e 5 R$ $M 1$ from chromosome 5R was probably homeologous to locus Vrn-Rl, previously known as Spl (Plashke 
et al. 1993), responsible for plant reaction for vernalization.

\section{Relationship between AA, PHS and HE}

Correlation between pairs of analyzed traits showed no significant relationship. AA and PHS also showed no correlation within two other mapping populations of rye (Twardowska et al. 2005), suggesting their independent genetic basis. However, it was found that QTL systems controlling PHS and AA partially overlap. Nine common QTL were detected, among 16 QTL for AA and 13 QTL for PHS (Masojć and Milczarski 2009). In the present study, six coinciding QTL for AA and PHS were found, which confirms the previous observations showing partial coincidence of the genomic regions controlling these two traits. Despite the higher density of our map, it is still not resolvable if loci for both traits are only linked or have pleiotropic effects. However, three perfectly overlapping QTL from chromosomes 1R, 3R and 6R, with the same markers linked both to AA and PHS QTL, make the second explanation probable. The fourth coinciding QTL from linkage group 6R had only a slight shift and the same marker linked, too. Such ideal or almost ideal matches of short intervals seem not to be accidental, taking into account that there is often no or weak correlation between QTL for one trait detected in different seasons.

There were no reports on the relationship between potentially related traits of PHS and HE in rye, except for the publication by Myśków (2011). The connection of PHS and HE in other crops is not well documented. PHS resistance was associated with later heading date (HD) in white wheat population. The mean HD and PHS scores were significantly negatively correlated ( $r=-0.39$ ), probably due to a major HD QTL found to be tightly linked to the PHS QTL on chromosome 2B (Munkvold et al. 2009). Despite the lack of correlation between PHS and HE, implying their independent genetic basis, there were as many as six coinciding QTL for both traits found. It shows that the relationship between PHS and both AA and HE is on the congruent level. However, such an ideal overlapping as between some QTL for AA and PHS was not observed, which suggests linkage rather than a pleiotropic effect of the revealed loci.

Additionally, one interval partially overlapping for all three studied traits was detected, which was the first report of this kind. The reason for co-localization of the QTL for two or all three target features remains unknown and requires developing studies. Future research involving fine mapping of these coinciding QTL may resolve whether the co-localized QTL represent a single locus with pleiotropic effect or whether there are two linked loci.

The present results show that there is no rule that plants prone to PHS reveal high activity of LMA. Similarly, earlier heading plants are not always early sprouting, and are then not susceptible to PHS in wet weather conditions. In any case, focusing on overlapping QTL should allow the choice of markers beneficial in the selection of plant materials with favorable values of PHS, AA and HE. This work reveals 55 markers linked to PHS and HE simultaneously, 30 to PHS and AA and one to AA and HE. Knowledge of DArT marker sequences enables their conversion to PCR markers, which are easy to use in MAS.

Acknowledgments This work was supported by the Ministry of Science and Higher Education, under a grant: NN302 361833, NN310 067639.

Open Access This article is distributed under the terms of the Creative Commons Attribution Noncommercial License which permits any noncommercial use, distribution, and reproduction in any medium, provided the original author(s) and source are credited.

\section{References}

Bolibok-Brągoszewska H, Heller-Uszyńska K, Wenzl P, Uszyński G, Kilian A, Rakoczy-Trojanowska M (2009) DArT markers for the rye genome-genetic diversity and mapping. BMC Genomics 10:578. doi:10.1186/14712164-10-578

Börner A, Korzun V, Voylokov AV, Worland AJ, Weber WE (2000) Genetic mapping of quantitative trait loci in rye (Secale cereale L.). Euphytica 116:203-209

Buck-Sorlin GH, Börner A (2001) Pleiotropic effects of the $e a_{7}$ photoperiod response gene on the morphology and agronomic traits in barley. Plant Breed 120:489-495

Chen A, Baumann U, Fincher GB, Collins NC (2009) Flt-2L, a locus in barley controlling flowering time, spike density, and plant height. Funct Integr Genomics 9:243-254

Cockram J, Jones H, Leigh FJ, OSullivan D, Powell W, Laurie DA, Greenland AJ (2007) Control of flowering time in temperate cereals: genes, domestication, and sustainable productivity. J Exp Bot 58(6):1231-1244

Doerge RW, Churchill GA (1996) Permutation tests for multiple loci affecting a quantitative character. Genetics 142: 285-294 
Graybosch RA, Guo Gang, Shelton DR (2000) Aberrant falling numbers of waxy wheats independent of $\alpha$-amylase activity. Cereal Chem 77(1):1-3

Jaccoud D, Peng K, Feinstein D, Kilian A (2001) Diversity arrays: a solid state technology for sequence information independent genotyping. Nucleic Acids Res 29(4):e25

Jamieson PD, Brooking IR, Semenov MA, Porter JM (1998) Making sense of wheat development: a critique of methodology. Field Crop Res 55:117-127

Korzun V, Malyshev S, Voylokov AV, Börner A (2001) A genetic map of rye (Secale cereale L.) combining RFLP, isozyme, protein, microsatellite and gene loci. Theor Appl Genet 102:709-717

Kulwal PL, Kumar N, Gaur A, Khurana P, Khurana JP, Tyagi AK, Balyan HS, Gupta PK (2005) Mapping a major QTL for pre-harvest sprouting tolerance on chromosome $3 \mathrm{~A}$ in bread wheat. Theor Appl Genet 111:1052-1059

Kunpu Z, Jichun T, Liang Z, Bin L, Guangfeng C (2009) Detection of quantitative trait loci for heading date based on the doubled haploid progeny of two elite Chinese wheat cultivars. Genetica 135:257-265

Laurie DA (1997) Comparative genetics of flowering time. Plant Mol Biol 35:167-177

Lewis S, Faricelli ME, Appendino ML, Válarik M, Dubkovsky J (2008) The chromosome region including the earliness per se locus Eps-Am1 affects the duration of early developmental phases and spikelet number in diploid wheat. J Exp Bot 59:3595-3607

Lunn GD, Major BJ, Kettlewell PS, Scott RK (2001) Mechanisms leading to excess alpha-amylase activity in wheat (Triticum aestivum L) grain in the UK. J Cereal Sci 33:313-329

Mares D, Mrva K (2008) Late-maturity a-amylase: low falling number in wheat in the absence of preharvest sprouting. J Cereal Sci 47:6-17

Mares D, Mrva K, Mui-Keng T, Sharp P (2002) Dormancy in white-grained wheat: progress towards identification of genes and molecular markers. Euphytica 126:47-53

Masojć P, Larsson-Raźnikiewicz M (1991) Genetic variation of $\alpha$-amylase levels among rye (Secale cereale L.) kernels, tested by gel diffusion technique. Swedish J Agric Res 21:141-145

Masojć P, Milczarski P (1999) Wykorzystanie mapy molekularnej genomu żyta i analizy QTL do identyfikacji genów warunkujących wczesność kłoszenia. Biul. IHAR 211:205-210

Masojć P, Milczarski P (2005) Mapping QTLs for alpha-amylase activity in rye grain. J Appl Genet 46:115-123

Masojć P, Milczarski P (2009) Relationship between QTLs for preharvest sprouting and alpha-amylase activity in rye grain. Mol Breed 23:75-84

Masojć P, Banek-Tabor A, Milczarski P, Twardowska M (2007) QTLs for resistance to preharvest sprouting in rye (Secale cereale L.). J Appl Genet 48:211-217

Masojć P, Wiśniewska M, Łań A, Milczarski P, Berdzik M, Pędziwiatr D, Pol-Szyszko M, Gałęza M, Owsianicki R (2011) Genomic architecture of alpha-amylase activity in mature rye grain relative to that of preharvest sprouting. J Appl Genet 52:153-160. doi:10.1007/s13353-010-0025-X

Mrva K, Mares DJ (1996a) Inheritance of late maturity $\alpha$-amylase in wheat. Euphytica 88:61-67
Mrva K, Mares DJ (1996b) Expression of late maturity $\alpha$-amylase in wheat containing gibberellic acid insensitivity genes. Euphytica 88:69-76

Mrva K, Mares D (1999) Regulation of high pI $\alpha$-amylase synthesis in wheat aleurone by a gene(s) located on chromosome 6B. Euphytica 109:17-23

Mrva K, Mares D (2002) Screening methods and identification of QTL associated with late maturity $\alpha$-amylase in wheat. Euphytica 126:55-59

Munkvold JD, Tanaka J, Benscher D, Sorrells ME (2009) Mapping quantitative trait loci for preharvest sprouting resistance in white wheat. Theor Appl Genet 119(7):1223-1235

Myśków B (2011) Identification of QTL for earliness and preharvest sprouting resistance in rye with using high density genetic maps of RIL populations (in polish). West-Pomeranian University Print, Szczecin, Poland (in print)

Myśków B, Masojć P, Banek-Tabor A, Szołkowski A (2001) Genetic diversity of inbred rye lines evaluated by RAPD analysis. J Appl Genet 42(1):1-14

Myśków B, Stojałowski S, Milczarski P, Masojć P (2010) Mapping of sequence specific markers and loci controlling pre-harvest sprouting and alpha-amylase activity on the genetic map of $\mathrm{F}_{2}(\mathrm{~S} 120 \times \mathrm{S} 76)$ rye (Secale cereale $\mathrm{L}$.) population. J Appl Genet 51(3):283-287

Plaschke J, Börner A, Xie DX, Koebner RMD, Schlegel R, Gale MD (1993) RFLP map ping of genes affecting plant height and growth habit in rye. Theor Appl Genet 85:1049-1054

Stojałowski S, Łapiński M (2002) Wykorzystanie techniki RAPD do konstruowania mapy sprzężeń u międzyliniowego mieszańca żyta. Zeszyty Problemowe Postępów Nauk Rolniczych 488:153-159

Tenhola-Roininen T, Kalendar R, Schulman AH, Tanhuanpää P (2011) A doubled haploid rye linkage map with a QTL affecting $\alpha$-amylase activity. J Appl Genet 52:299-304. doi:10.1007/s13353-011-0029-1

Tjin Wong Joe AF, Summers RW, Lunn GD, Atkinson MD, Kettlewell PS (2005) Pre-maturity $\alpha$-amylase and incipient sprouting in UK winter wheat, with special reference to the variety Rialto. Euphytica 143:265-269

Twardowska M, Masojé P, Milczarski P (2005) Pyramiding genes affecting sprouting resistance in rye by means of marker assisted selection. Euphytica 143:257-260

Van Ooijen JW (2004) MapQTL ${ }^{\circledR} 5$ Software for the mapping of quantitative trait loci in experimental populations. Kyazma B.V, Wageningen

Van Ooijen JW, Voorrips RE (2001) JoinMap ${ }^{\circledR}$ 3.0 Software for the calculation of genetic linkage maps. Plant Research International, Wageningen

Wang S, Basten CJ, Zeng Z-B (2007) Windows QTL Cartographer 2.5. Department of Statistics, North Carolina State University, Raleigh, NC. (http://statgen.ncsu.edu/qtlcart/ WQTLCart.htm)

Wang RX, Hai L, Zhang XY, You GX, Yan CS, Xiao SH (2009) QTL mapping for grain filling rate and yield-related traits in RILs of the Chinese winter wheat population Heshangmai $\times$ Yu8679. Theor Appl Genet 118:313-325

Worland AJ, Börner A, Korzun V, Li WM, Petrovic S, Sayers EJ (1998) The influence of photoperiod genes on the adaptability of European winter wheats. Euphytica 100:385-394

Zeng Z-B (1994) Precision mapping of quantitative trait loci. Genetics 136:1457-1468 